\title{
DOS JOGOS POPULARES À CULTURA CORPORAL DE MOVIMENTO NA EDUCAÇÃO FÍSICA: REFLEXÕES ACERCA DO DESENVOLVIMENTO DA CONSCIÊNCIA DA CRIANÇA
}

Larissa Zangarini Antonio; Irineu Aliprando Tuim Viotto Filho; Rodrigo Lima Nunes.

Universidade Estadual Paulista - UNESP, Curso de Educação Física, Presidente Prudente, SP. E-mail: larissa zangarini01@hotmail.com.

\section{RESUMO}

Este trabalho foi desenvolvido pelo Grupo de Estudos Intervenções e Pesquisa em Educação Escola- Teoria Historico-Cultural (GEIPEE-thc) a partir de intervenções pedagógicas efetivadas em um projeto de extensão, realizado no interior do Laboratório de Atividades Ludo-Pedagógicas (LAR) do departamento de Educação Física -UNESP- Presidente Prudente/SP. O objetivo é apresentar uma proposta de intervenção que busca resgatar a importância dos jogos populares como ponto de partida e enfatiza os jogos desportivos, a dança a ginástica e as lutas como ponto de chegada da construção da consciência crítica das crianças. Tomamos os jogos populares como uma prática social inicial para a motivação das crianças e avançamos na socialização dos objetos mais desenvolvidos da cultura corporal de movimento, com a finalidade de fazer movimentar o processo de aprendizagem e desenvolvimento desses sujeitos numa direção qualitativamente superior. Essa proposição nos remete à necessidade de construção de processos ludopedagógicos, pois congregam ensino e ludicidade no processo de construção da consciência e humanização dos sujeitos.

Palavras-Chave: Educação Física, Jogos populares, Teoria Histórico-Cultural.

\section{THE POPULAR GAMES AND THE BODY CULTURE OF MOVEMENT IN PHYSICAL EDUCATION: REFLECTIONS THROUGH THE DEVELOPMENT OF CHILD CONSCIOUSNESS}

\begin{abstract}
This work was developed by the Group of Studies, Intervention and Research in School Education Cultural Historical Theory (XXXXX-thc) based on pedagogical interventions carried out in an extension project, carried out inside the XXXX of the Department of Physical Education -UNESPPresidente Prudente / SP. The objective is to present an intervention proposal that seeks to rescue the importance of popular games as a starting point and emphasizes sports games, dance the gymnastics and the fights as the point of arrival of the construction of children's critical awareness. We take the popular games as an initial social practice for the motivation of children and advance in the socialization of the more developed objects of the body culture of movement, in order to move the learning process and development of these subjects in a qualitatively superior direction. This proposition reminds us of the need to construct ludo-pedagogical processes, since they bring together teaching and playfulness in the process of constructing the consciousness and humanization of the subjects.
\end{abstract}

Keywords: Physical Education, Popular Games, Cultural Historical Theory. 


\section{INTRODUÇÃO}

O processo de construção desse trabalho efetivou-se a partir de intervenções ludopedagógicas realizadas em um projeto de extensão do Grupo de Estudos Intervenções e Pesquisa em Educação Escola - Teoria Historico-Cultural (GEIPEEthc) efetivado no interior do Laboratório de Atividades Ludo-Pedagógica (LAR) com crianças de 06 a 10 anos que apresentam dificuldades de aprendizagens e oriundas de escolas públicas de Presidente Prudente/SP.

Baseados na perspectiva teórico-filosófica e metodológica da Teoria Histórico-Cultural e do Materialismo Histórico Dialético, tivemos a intenção de fundamentar nossas intervenções e possibilitar a transformação qualitativa dos processos psíquicos superiores das crianças, tendo em vista a construção da consciência crítica desses indivíduos, iniciando as atividades pelos jogos populares até chegarmos a outros objetos mais desenvolvidos da cultura corporal de movimento, dentre eles, o esporte, a dança, a ginástica e as lutas.

Como é sabido, a área tecnológica está em grande expansão no meio social, o que facilita o acesso das crianças aos meios eletrônicos e digitais, tais como Videogames, computadores, Smartphones, MP3, Tablets, dentre outros. Tal situação faz com que as crianças ocupem grande parte de seu tempo com redes sociais e jogos eletrônicos, o que as levam, consequentemente, a uma vida sedentária, restrita ao âmbito de sua própria casa, mantendo uma sociabilidade, na maior parte do tempo, somente virtual.

Essa realidade tem gerado transformações em todos os aspectos da sociedade, levando as crianças a uma maior facilidade ao acesso a diferentes informações, possibilitando, também, uma nova forma de comunicação, qual seja, a virtual. No entanto, apesar da agilidade que essa forma de comunicação oferece, ela pode levar as crianças e jovens, além de terem, possivelmente, uma vida sedentária e restrita a um meio social limitado, a processos de alienação de suas consciências, fato preocupante na atualidade.

Nesse sentido, notamos cada vez mais que os contatos pessoais entre as crianças e jovens tem se tornado limitado, levando-as a terem um contato menor (ou inexistente) com brincadeiras de forma geral e, especificamente, as brincadeiras populares, inclusive na escola. Notamos que a substituição dos jogos populares e brincadeiras de rua, praças e etc. tem sido provocada pela grande aproximação, da maioria das crianças, aos jogos eletrônicos e virtuais, os quais podem ser praticados nas suas próprias casas, distanciando as crianças de relações interpessoais autênticas.

Antigamente era comum vermos nos bairros das cidades, principalmente nas ruas, parques e praças, as crianças brincando de queimada, pé-na-lata, pega-pega, mãe da rua, garrafão, mortovivo, dentre outras brincadeiras populares coletivas, as quais, pela sua natureza e especificidade, sempre possibilitaram o desenvolvimento motor, psicomotor, psicológico e social das crianças e jovens. Contudo, atualmente, o brincar tornou-se uma atividade limitada a espaços privados das residências, ou direcionadas a utilização de aparelhos eletrônico-digitais.

Queremos enfatizar que a atividade do brincar, segundo a teoria histórico-cultural, tornase vital na vida das crianças, desde o brincar nos espaços públicos, na escola, como também nos espaços privados das próprias casas, desde o jogo popular até os jogos desportivos e outros elementos da cultura corporal de movimento. Segundo Leontiev $(1998$, p.121) é por meio da brincadeira que a criança "tenta integrar uma relação ativa não apenas com as coisas diretamente acessíveis a ela, mas também com o mundo mais amplo, isto é, ela se esforça para agir como um adulto" (LEONTIEV, 1998, p.121). Podemos compreender que pela atividade do brincar a criança se apropria dos objetos culturais construídos historicamente pelo conjunto de homens, sendo que essa atividade torna-se fundamental na educação escolar.

É por meio da (o) brincadeira/jogo que a criança experimenta, descobre e inventa novas formas de manifestação da sua subjetividade, sendo que o objeto da (o) brincadeira/Jogo surge com a intenção de proporcionar curiosidade, estimular e superar o desejo de descobrir o novo e reconstruir as ações humanas com as quais ela tem contato em seu cotidiano (LEONTIEV, 2006; 
ELKONIN, 1998). Sendo assim, nessa esfera de ações lúdicas, o desenvolvimento de habilidades e capacidades humanas é impulsionado pelo brincar, atividades esta que, por excelência, é indispensável para o processo de aprendizagem e desenvolvimento das crianças em idade préescolar e escolar inicial.

Segundo a Mukhina (1995) a (o) brincadeira/Jogo possibilita o desenvolvimento da atenção, memória, imaginação, linguagem e comportamentos, dentre outras capacidades humanas. Assim ao jogar a criança precisa se concentrar e recordar representações específicas da situação lúdica, manipular substitutos de objetos, conferindo-lhes outros significados, dialogando com seus pares e agindo como se fossem outras pessoas.

Assim podemos considerar que o jogo e a brincadeira são atividades especificamente humanas, que se constituem e se desenvolvem a partir da relação interpessoal dos seres humanos influindo em seu desenvolvimento intrapessoal, sendo que tal atividade é a que melhor proporciona a relação da criança com o mundo adulto, no sentido de permitir a máxima apropriação das produções culturais historicamente elaboradas (NUNES; VIOTTO FILHO, 2006).

Salientamos que para a efetivação de jogos e brincadeiras que caminhem na direção efetiva de desenvolvimento das crianças, torna-se indispensável o papel do professor nesse processo, possibilitando às crianças, a partir de uma mediação intencionalmente planejada, vivências que possibilitem o desenvolvimento qualitativo de suas consciências, contribuindo assim para o processo de humanização de tais indivíduos.

Desta maneira reconhecemos que os jogos populares resgatam vivências, representações e relações sociais próprias de sua vida cotidiana com outras crianças, parentes e adultos à sua volta, sendo que os professores na escola, precisam tomar essa referência como importante ponto de partida para o seu trabalho educativo e, desta forma, proporcionar condições para que as crianças avancem na direção de formas diferenciadas e mais complexas de jogar e brincar, dentre elas os jogos desportivos, a dança, a ginástica e as lutas, considerando que esses elementos da cultura corporal tornam-se fundamentais ao processo de desenvolvimento mais elaborado das funções psíquicas especificamente humanas, tendo em vista a sua maior complexidade.

As brincadeiras e jogos populares são considerados como parte da cultura, sendo transmitidos de geração para geração principalmente através da oralidade e de vivências cotidianas assistemáticas. Muitos jogos ou brincadeiras preservam sua estrutura inicial, outras se modificam, recebendo novos conteúdos (FADELI; FERRI; SILVA; GONÇALVES, 2003). Assim, defendemos que o avanço social e histórico dos jogos populares caminhou para a elaboração de elementos mais desenvolvidos da cultura corporal, os quais foram citados anteriormente.

Entendemos como cultura corporal de movimento o objeto de estudo da Educação Física que pode ser entendida como uma parte da cultura humana, apresentando conteúdos específicos que foram e são determinados pela corporeidade humana, produzidos historicamente pela humanidade. Segundo Betti (1993), a cultura corporal de movimento abrange o domínio de valores e padrões de atividade física, voltado a pensar na coerência do pensamento científico em sua relação com a sociedade.

Podemos compreender que através da prática da cultura corporal do movimento, sobretudo na escola, as crianças estarão avançando na construção de uma consciência mais complexa, não limitada ao cotidiano e ao senso comum presente, muitas vezes, nos jogos populares, desenvolvendo assim, sob mediação do professor, funções psicológicas superiores, capacidades e habilidades físicas e psicomotoras mais elaboradas.

Nossa defesa neste trabalho aponta, então, frente a todo o contexto apresentado anteriormente, a necessidade de efetivação de um conjunto de intervenções ludo-pedagógicas, iniciando pelos jogos populares e alcançando os jogos desportivos, à dança, à ginástica e às lutas, como possibilidade de superação da acomodação e alienação que pode ser possibilitada pelos jogos eletrônicos, contribuindo, também, com uma maior complexificação em relação ao 
desenvolvimento da consciência das crianças, a partir de uma mediação intencional do professor de Educação Física.

Enfatizamos que não temos a pretensão de desvalorizar os jogos eletrônicos em relação às possíveis contribuições que os mesmos podem oferecer no que tange a aprendizagem e desenvolvimento das crianças, contudo, torna-se evidente uma visão crítica acerca de tal realidade, tendo em vista que ela tem se configurado enquanto hegemônica na vida diária das crianças, o que pode ocasionar processos, muitas vezes, limitantes de seu desenvolvimento.

\section{ASPECTOS METODOLÓGICOS}

No sentido de demonstrar o quanto as crianças precisam brincar e se apropriar de brincadeiras e jogos, desde os populares, até os mais desenvolvidos da cultura corporal, não se limitando aos jogos tecnológicos e eletrônicos, realizamos um projeto de intervenção no interior do LAR, no intuito de demonstrar que, através da Teoria Histórico-Cultural, podemos construir atividades pedagógicas críticas e transformadoras no sentido de possibilitar um desenvolvimento mais elaborado da consciência das crianças, pela via de atividades ludo-pedagógicas planejadas e efetivadas de forma intencional e direta pelo professor de Educação Física (NUNES \& VIOTTO FILHO, 2016).

Ressaltamos que as atividades de intervenção ludo-pedagógica foram realizadas no LAR e aconteceram semanalmente, com duração de 90 minutos ao longo de 16 encontros. As crianças participantes estavam na faixa etária de 06 a 10 anos de idade, oriundas de escolas públicas da cidade de Presidente Prudente/SP, as quais são encaminhadas ao LAR pelos seus professores e coordenadores pedagógicos, apresentando queixas de dificuldade de aprendizagem escolar ou deficiências intelectual, motora e psicomotora.

\section{O PROCESSO INTERVENTIVO E SUA ANÁLISE E CONSIDERAÇÕES}

Para este artigo apresentaremos os dados decorrentes do processo de intervenção realizado, sendo que discutiremos o processo de ascensão dos jogos populares aos jogos desportivos, dança, ginástica e lutas e sua importância na construção da consciência crítica das crianças, passando pela crítica aos jogos eletrônicos que, de certa forma, tem tomado conta da vida das crianças levando-as ao sedentarismo e restringindo suas relações sociais.

Iniciamos o processo questionando as crianças sobre o que eles entendiam por "Jogos populares" e qual a importância desses jogos para o seu desenvolvimento. Tivemos também uma discussão sobre a diferença entre Jogo e Esporte e explicamos os jogos populares, assim como as diferenças entre jogo, esporte, brincadeira, etc e pedimos para que listassem os tipos de jogos que realizavam no seu bairro e com sua familia. Neste processo, também discutimos sobre as regras dos jogos, suas origens, regras e diferentes formas de realização e a variação na denominação desses jogos. Debatemos com as crianças sobre essas especificidades dos jogos populares e discutimos sobre a diversidade cultural e regional de cada sujeito no que se refere ao conhecimento e prática de tais jogos.

Ao longo dos encontros iniciais propusemos que as crianças perguntassem para os pais e familiares, assim como para colegas e vizinhos, sobre as brincadeiras que realizavam no passado, com a finalidade de discutir sobre o processo de transformação cultural das brincadeiras/Jogos, suas regras e outras características que se diferenciavam devido à diversidade contextual e cultural dos sujeitos.

Houve também um momento importante de entendimento sobre o que é Jogo popular por parte das crianças, sendo que as mesmas deveriam desenhar as brincadeiras que os seus pais e familiares realizavam e pedimos, ainda, que comparassem com as brincadeiras que atualmente realizam. Nesse momento, ficou evidente, o quanto as brincadeiras estavam limitadas aos jogos eletrônicos e que os indivíduos escolares, pouco brincavam com os amigos ou mesmo vizinhos, 
dada a necessidade de manterem-se seguros dentro de suas casas e terem o computador ou smartphone para se divertirem.

Também tivemos momentos de confronto dos desenhos construídos sobre as brincadeiras populares de seus pais e familiares com a realidade atual, no sentido de possibilitar uma reflexão crítica sobre a realidade, enfatizando que os jogos populares tem sua importância por aglutinarem as pessoas e possibilitarem relações sociais amistosas e agradáveis entre as pessoas da família, vizinhos e amigos do bairro.

Considerando que a questão dos jogos populares já era de domínio das crianças, possibilitamos experiências de criação de seus próprios brinquedos, mais uma vez oportunizando uma reflexão crítica sobre a supremacia dos jogos eletrônicos em suas vidas. Tal processo de confecção dos brinquedos pelas crianças (Pipa; Peteca, Vai-e-Vem e os Pé-de-Lata), valorizaram possibilidades de criação pelos sujeitos e, sobretudo, a ampliação de suas vivências durante o processo de intervenção. Enfatizamos que os novos brinquedos poderiam ser levados para a casa, no sentido de brincar com os primos, amigos, pais e vizinhos.

Com o avanço das crianças no que se refere à sua interação social, compreensão dos jogos populares e crítica aos jogos eletrônicos, decidimos pela promoção de práticas mais elaboradas a partir dos objetos da cultura corporal do movimento (Brach, 2007). Nesta etapa, pedimos para que as crianças em grupos discutissem sobre os aspectos voltados aos jogos, os esportes, as ginásticas, as danças, as lutas, proporcionando uma prática não competitiva, com o objeto de promover o seu desenvolvimento integral.

Ao final do processo de intervenção buscamos debater sobre a importância das brincadeiras realizadas na promoção da prática dos objetos da cultura corporal de movimento. Foi importante identificar o quanto as crianças valorizaram a aprendizagem de esportes, danças, da ginástica e lutas, afirmando que a prática dos jogos foi importante para aprender a ouvir os companheiros de equipe, compreender e discutir as regras, chegar em acordos táticos, estratégias de jogo, união da equipe e etc., fatores que consideramos essenciais para o processo de desenvolvimento e humanização das crianças, principalmente para o seu processo de escolarização.

Para a finalização do processo, proporcionamos vivências de algumas práticas desportivas diferenciadas, no sentido de mostrar novas possibilidades e incitar um maior desenvolvimento da consciência dos sujeitos. Realizamos o "Futebol com as mãos", "Vôlei de sabão" e "Badminton", sendo que, após discussão coletiva, fazíamos as adaptações das regras à nossa realidade.

Após as variadas vivências dos diferentes objetos da cultura corpora, ainda possibilitamos um momento de criação, pelas crianças, de um esporte, com regras, objetivos, local de prática e quantidade de participantes, definindo tal atividade como um esporte não-convencional. Tal vivência teve a finalidade de criar condições de discussão do que está instituído enquanto hegemônico na sociedade, engendrar processos de criatividade e observar o quanto as crianças haviam se apropriado dos conteúdos proporcionados durante todo o processo interventivo.

Enfim, após os 16 encontros realizados com as crianças, desde os jogos populares, até chegarmos aos jogos e atividades mais complexas da cultura corporal de movimento, como também ao questionarmos a importância de sua contínua transformação e evolução, dado o movimento dialético presente na sociedade e do conhecimento produzido, conseguimos realizar uma síntese importante para discutirmos o papel da Educação Física, principalmente aquela que acontece na escola, como importante possibilidade educativa de construção de consciências críticas.

Consideramos que a passagem dos jogos populares, assim como a crítica aos jogos eletrônicos, até chegarmos aos jogos mais complexos e próprios da cultura corporal de movimento, engendraram condições de avanço da consciência das crianças, sobretudo porque a orientação dos interventores do GEIPEEthc foi essencial nesse processo, garantindo orientações e 
críticas para transmitir conhecimentos essenciais sobre os esportes, a dança, a ginástica, as lutas e outros conhecimentos fundamentais a serem apropriados pelas crianças.

Defendemos assim que o professor de Educação Física assume importância fulcral no processo de aprendizagem e desenvolvimento das crianças na escola, pois não defendemos o brincar natural e espontâneo, mas sim, a atividade coletiva do brincar, devidamente orientada e trabalhada pelo professor, a qual, sim, pode iniciar-se nos jogos populares, de bairro, como salientamos, mas, necessariamente, deve levar as crianças à apropriação de jogos mais desenvolvidos, sempre numa perspectiva lúdica, coletiva e crítica.

No interior do LAR temos defendido que a atividade do jogo e da brincadeira deve estruturar-se como atividade ludo-pedagógica, respeitando as diferentes situações sociais de desenvolvimento dos estudantes, suas condições objetivas de vida e o contexto social e cultural no qual se encontram. A atividade ludo-pedagógica, portanto, deve constituir-se como atividade educativa humanizadora, na direção da superação das brincadeiras espontâneas que reproduzem o cotidiano formal e alienado da sociedade capitalista.

O professor de Educação Física, imbuído de pressupostos histórico-críticos, é imprescindível nesse momento, ao realizar suas aulas e assumir o papel de sujeito mais desenvolvido, que socializa os jogos e as brincadeiras, assim como outros objetos da cultura corporal, tomando a atividade ludo-pedagógica como um instrumento educativo e de construção da consciência humana na escola (FÉLIX, 2013; NUNES; 2013; NUNES E VIOTTO FILHO, 2016).

Enfim, temos defendido, ao lado dos membros do GEIPEEthc que a Educação Física precisa apresentar-se como efetivamente educativa e para isso, além de respaldar-se numa fundamentação filosófica histórico-crítica como afirmamos, precisa situar-se como prática pedagógica crítica, como a firma Bracht (2007) e, situar-se no plano do desenvolvimento motor, psíquico e social dos indivíduos, assumindo sua responsabilidade na construção das consciências dos alunos na escola numa direção humanizadora (NUNES, 2013; NUNES E VIOTTO FILHO, 2016).

\section{REFERÊNCIAS}

BETTI, M; ZULIANI, L. R. Revista Mackenzie de Educação Física e Esporte. V.I, n.1, p. 73-81, 2002.

BRACHT, V. Educação Física e Ciência: cenas de um casamento (in) feliz. ljui: UNIJUI, 2007.

COLETIVO DE AUTORES. Metodologia do ensino de educação física. São Paulo: Cortez, 1992.

Elkonin, D.B.Psicologia do Jogo. São Paulo; Martins Fontes, 1998.

FADELI, Thiagi TOZETTI; FERRI, Marco. A PARENTE; SILVA, Roseli Sandra E; GONÇALVES JUNIOR, Luiz. Arco da velha: resgate e vivência de brinquedos e brincadeiras populares. In: XV ENCONTRO NACIONAL DE RECREAÇÃO E LAZER - LAZER E TRABALHO: NOVOS SIGNIFICADOS NA SOCIEDADE CONTEMPORÂNEA, 2003, Santo André.

FELIX, T. S. P. Timidez na escola: um estudo histórico-cultural. Presidente Prudente: UNESPPrograma de Pós-graduação em Educação (Dissertação de mestrado), 2013.

LEONTIEV,A.N. Os princípios Psicológicos da Brincadeira Pré-escolar. In: Vigotskii, I. S.; LURIA,A.R.; LEONTIEV, A.N. Linguagem, desenvolvimento e aprendizagem. São Paulo: ícone, 2006

NUNES, R. L. Atividade do jogo e desenvolvimento infantil: implicações sociais para a construção da consciência da criança na escola. Presidente Prudente: UNESP-Programa de Pós-graduação em Educação (Dissertação de mestrado), 2013. 
NUNES, R.L.; VIOTTO FILHO, I.A.T. A atividade do jogo e suas implicações para o desenvolvimento da consciência da criança na escola. Curitiba: CRV, 2016.

MUKHINA, A.Psicologia da idade pré-escolar. São Paulo: Martins Fontes, 1995. 